\title{
Performance Evaluation of Air Assisted Intra Canopy Sprayer in Cotton Crop
}

\author{
Satyanarayan $^{1 *}$, K.V. Prakash ${ }^{1}$, M. Anantachar ${ }^{1}$, M. Veerangouda ${ }^{1}$, \\ Satyanarayana Rao ${ }^{2}$ and A.G. Sreenivas ${ }^{3}$ \\ ${ }^{1}$ Department of Farm Machinery and Power Engineering, College of Agricultural \\ Engineering, University of Agricultural Sciences, Raichur- 584 104, India \\ ${ }^{2}$ Department of Agronomy, Research Institute on Organic Farming, University of Agricultural \\ Sciences, Raichur - 584 104, India \\ ${ }^{3}$ Department of Entomology, College of Agriculture, University of Agricultural Sciences, \\ Raichur - 584 104, India \\ *Corresponding author
}

\section{A B S T R A C T}

\section{Keywords}

Canopy sprayer, Air assistance, Droplet density, Air velocity

Article Info

Accepted:

04 October 2019

Available Online:

10 November 2019
Pesticide application is a complex process and the magnitude and uniformity of spray deposition is mainly influenced by target canopy characteristics, type of spray equipment and mode of operation and properties of spray chemicals. In the present context, application of pesticides from top of the plant results in poor penetration of the pesticide to desired locations where insects lay their eggs or hide in other stages of their growth. Considering the above factors into account, a bullock drawn air assisted Intra canopy sprayer was developed at the College of Agricultural Engineering, Raichur. The developed sprayer was tested in the research farm for spraying on cotton crop using a pair of bullock (Breed: Khillari) under physiological limits of bullocks with visual fatigue symptoms. The average field capacity of intra canopy sprayer was found to be $0.80 \mathrm{ha} \mathrm{h}^{-1}$. The swath width of spray was found as $3260 \mathrm{~mm}$. The increased height of boom from 15 to $45 \mathrm{~cm}$ caused the higher swath width of spray. The cost of operation worked out for bullock drawn air assisted Intra canopy sprayer for spraying on cotton crop was Rs. $540.50 \mathrm{ha}^{-1}$. The saving in time and cost for spraying on cotton crop using bullock drawn intra canopy sprayer was found to be $88.43 \%$ and $82.24 \%$ respectively.

\section{Introduction}

Cotton (Gossypium sps) is a commonly grown crop grown by the farmers in Raichur region of Karnataka. The cotton is grown both in rain fed and in irrigated condition using canal water in command area of Upper Krishna Irrigation Project and Tungabhadra Irrigation 
Project. Normally, these cotton crops require 3 to 4 times spraying operation for the control of pests and diseases. A manually operated knapsack sprayer can cover 0.4 ha day ${ }^{-1}$ of 6 working hours and a motorized knapsack sprayer fitted with petrol engine can cover 1.2-1.6 ha day ${ }^{-1}$ of 6 working hours in Raichur District. The farmers generally used the engine operated HTP sprayer mounted in the cart for spraying purpose. However, the uniformity of spraying is not achieved with manually operated sprayer. As the height of the crop and its density increases with the stage of the crop, the effectiveness of manually operated spraying decreases.

However, it is revealed that, tractor operated sprayers normally cause plant damage due to its less ground clearance and present boom sprayers cover only top of the plant leaving the middle and bottom portion untreated.

Hence, the bullock power has been selected as power source for pulling the cart, the sprayer is being operated by the engine as power source and bullock cart acts as a traction device for installation of Intra canopy sprayer. The bullock cart provides more ground clearance and does not make the way for plant damage during spraying operation.

The pest and diseases control can be effectively carried out when the suitable sprayer sprays the chemical solution covering top, side and bottom side of the plant canopy. There is a need to develop Intra canopy sprayer which can be mounted over the bullock cart for carrying out spraying operation for the selected field crops.

Keeping in view of the above facts, the research work pertaining to the spraying operation, the bullock cart mounted Intra canopy sprayer was developed to improve the spray deposition and to reduce the drudgery of human labour.

\section{Materials and Methods}

\section{Development of bullock drawn intra canopy sprayer}

The fabrication and development of intra canopy sprayer has been carried out at College of Agricultural Engineering, Raichur during the year 2014-15 and its evaluation has been carried out 2015-16 for the cotton crop. Based on the requirement of cotton and other row crops and power available in the sprayer, spray boom system was designed and developed to spray the liquid on the plant to cover its complete canopy. The spray boom consists of both horizontal (1 No) and vertical spray boom (4 No) fitted with nine number of hollow cone spray nozzles. Nozzles were arranged in such a way that one nozzle can spray the liquid from top side of the plant canopy. One nozzle was mounted with cup type of structure to receive air from the boom with liquid to two vertical sleeve booms in opposite direction to cover the middle and bottom of the plant canopy.. The spray boom was divided to cover three rows based on crop row spacing of $1 \mathrm{~m}$. Nozzle was mounted on top side spraying for every $50 \mathrm{~cm}$ in between the $1 \mathrm{~m}$ length and for vertical boom, one nozzle mounted at $40 \mathrm{~cm}$ and one nozzle mounted at $80 \mathrm{~cm}$ in opposite direction to cover whole plant canopy. Boom was designed to cover three rows.

The sprayer is provided with water tank of 200 1 capacity. The water tank was fixed over the frame by fabricating it using MS angle having the dimensions of $950 \times 750 \times 350 \mathrm{~mm}$ and flat frame also having the dimensions of $380 \times$ $250 \times 5 \mathrm{~mm}$. The sprayer tank is made of PVC material and fixed firmly over the frame for storing the chemical solution. Impeller type air blower has been used to discharge of air 1 $\mathrm{m}^{3} / \mathrm{s}$ mounted on the frame through nut and bolt system. The power generated by the engine is transferred to the pump fitted 
adjacent to the engine through $\mathrm{V}$-belt drive. The intra canopy sprayer basically consists of the different functional components such as spray boom (horizontal: 1 No. and vertical boom: 4 No.), air blower, HTP pump, pressure gauge, diesel engine, self starter and spray tank. All these functional components were designed, fabricated and installed over a bullock cart. A pair of bullock was used as a power for traction purpose and sprayer was operated using diesel engine.

A Self starter arrangement has been made with diesel engine for operating the canopy sprayer and self starter button is placed near by the operator for easy working during operation. The self starter starts the diesel engine without cranking the handle. The specification of air assisted intra canopy sprayer is presented in Table 1.

\section{Calibration of bullock drawn intra canopy sprayer under laboratory conditions}

Crop parameters of cotton such as rows spacing, plant to plant distance, height of crop etc., were measured. For spraying operation, the recommended chemical solution as per the crop requirement was prepared separately in a tank. The chemical solution was thoroughly mixed and the same solution was poured in to the chemical tank of spraying machine and also filtered it (Veerangouda et al., 2014). The wheel adjustments were carried out in accordance with the row spacing of the crop. The field performance of developed intra canopy sprayer was carried out in an area of one hectare of cotton crop in research farm. During the field trials, speed of operation, swath width, draft, fuel consumption, and discharge rate were measured with the selected variables for the study such as air velocity of $12 \mathrm{~m} \mathrm{~s}^{-1}$, operating pressure of 10 $\mathrm{kg} \mathrm{cm}^{-2}$ and three different heights of boom from top of plant. The physiological response of bullocks and behavioural symptoms were observed during work-rest schedule before and after spraying operation. The cost of operation for this sprayer has been worked out.

\section{Results and Discussion}

The developed bullock drawn air assisted intra canopy sprayer was operated with three replications with the selected variables on cotton crop in research farm. The field trials were carried out under work-rest schedule to assess the physiological response of bullocks for developing fatigue scores within limits. The biometric parameters of cotton crop crop in the field were measured and are presented in the Table 2. The cotton crop (variety: $B t$ MRC -7351) planted at row spacing of 900 $\mathrm{mm}$ with plant to plant distance in a row of $600 \mathrm{~mm}$ was selected for the field trials. The average height of crop was $1200 \mathrm{~mm}$ at crop standing period of 120 days. Among the pests of cotton, cotton bollworms viz., American bollworm (Helicoverpa armigera), Pink bollworm (Pectinophora gossypiella) and spotted bollworms (Earias vitella) cause significant yield losses.

During field trials, the biometric data pertaining to cotton such as row to row spacing, height of crop and stage of crop were noted. Before spraying operation, the wheel treads of the machine and spray boom height were adjusted according to row spacing and the height of crop. For spraying operation, the recommended chemical solution as per the plant requirement was prepared separately in the tank. The chemical solution was thoroughly mixed and the same solution was poured into the chemical tank of the sprayer. In order to provide protection for operator the protective clothes, hand gloves and face cover glass were utilized to avoid any harmful effects for the operator during the field trials. The working of bullock drawn air assisted intra canopy sprayer for cotton crop in the 
research farm is shown in Plate 1 and Plate 2. The field performance results of bullock drawn engine operated sprayer for pigeon pea crop carried out in the research farm is presented in the Table 3 .

From the Table 3, it is revealed that the sprayer was capable to cover three rows at a time using a spray boom in which nine spray nozzles were fixed in opposite direction to spray top, middle and at the bottom of the plant leaves. The boom height was adjusted in accordance with the height of cotton crop. The sprayer was operated at air velocity of $10 \mathrm{~m} \mathrm{~s}^{-1}$ and operating pressure of $20 \mathrm{~kg} \mathrm{~cm}^{-2}$, giving an average discharge of $1200 \mathrm{l} \mathrm{ha}^{-1}$ at the forward speed of $2.7 \mathrm{~km} \mathrm{~h}^{-1}$. Air velocity was maintained was $12 \mathrm{~m} \mathrm{~s}^{-1}$ and the operating pressure was maintained at constant level by locking the throttle lever at $10 \mathrm{~kg} \mathrm{~cm}^{-2}$. The sprayer exerted a draft of $758.82 \mathrm{~N}$ during spraying operation. The average field capacity of the sprayer was found to be $0.80 \mathrm{ha} \mathrm{h}^{-1}$. The total quantity of chemical solution sprayed during the experiment was $12001 \mathrm{ha}^{-1}$. Saving in cost and time obtained was 82.24 and 88.43 $\%$ respectively. The bullock drawn air assisted intra canopy sprayer worked satisfactorily during the field trials.

Table.1 Specifications of bullock drawn air assisted Intra canopy sprayer

\begin{tabular}{|c|c|c|}
\hline Sl. no. & Parameters & Value \\
\hline 1 & $\begin{array}{l}\text { Overall dimensions, } \\
(\mathrm{L} \times \mathrm{W} \times \mathrm{H}), \mathrm{mm}\end{array}$ & $4000 \times 1240 \times 2120$ \\
\hline 2 & Weight $(\mathrm{kg})$ & 320 \\
\hline 3 & Power source for spraying & 5 hp Diesel engine \\
\hline 4 & Engine speed, rpm & 1600 \\
\hline 5 & Power source for pulling of cart & A pair of bullock \\
\hline 6 & Type of Pump & HTP Pump \\
\hline 7 & Pump capacity & $3 \mathrm{hp}$ \\
\hline 8 & Pump speed, rpm & 900 \\
\hline 9 & Pressure control device & Pressure relief valve \\
\hline 10 & Blower type & Axial flow blower \\
\hline 11 & Blower shaft speed, rpm & 1620 \\
\hline 12 & Power transmission & Belt and pulley drive \\
\hline 13 & Number of nozzles & 9 \\
\hline 14 & Nozzle spacing & $50 \mathrm{~cm}$ \\
\hline 15 & Type of nozzle & Hollow cone \\
\hline 16 & Air velocity in each air duct & $20-25 \mathrm{~m} \mathrm{~s}^{-1}$ \\
\hline 17 & Horizontal boom length, mm & 3500 \\
\hline 18 & Vertical boom length, mm & 1000 \\
\hline 19 & Height of boom & Adjustable as per requirements \\
\hline 20 & Wheel, mm & Diameter 1000, width 100 \\
\hline 21 & Ground clearance, $\mathrm{mm}$ & 1200 \\
\hline 22 & Tank capacity, 1 & 200 \\
\hline 23 & Walking speed of bullock, $\mathrm{km} \mathrm{h}^{-1}$ & $2-3.5$ \\
\hline 24 & Cost of sprayer, Rs. & 90,000 \\
\hline
\end{tabular}




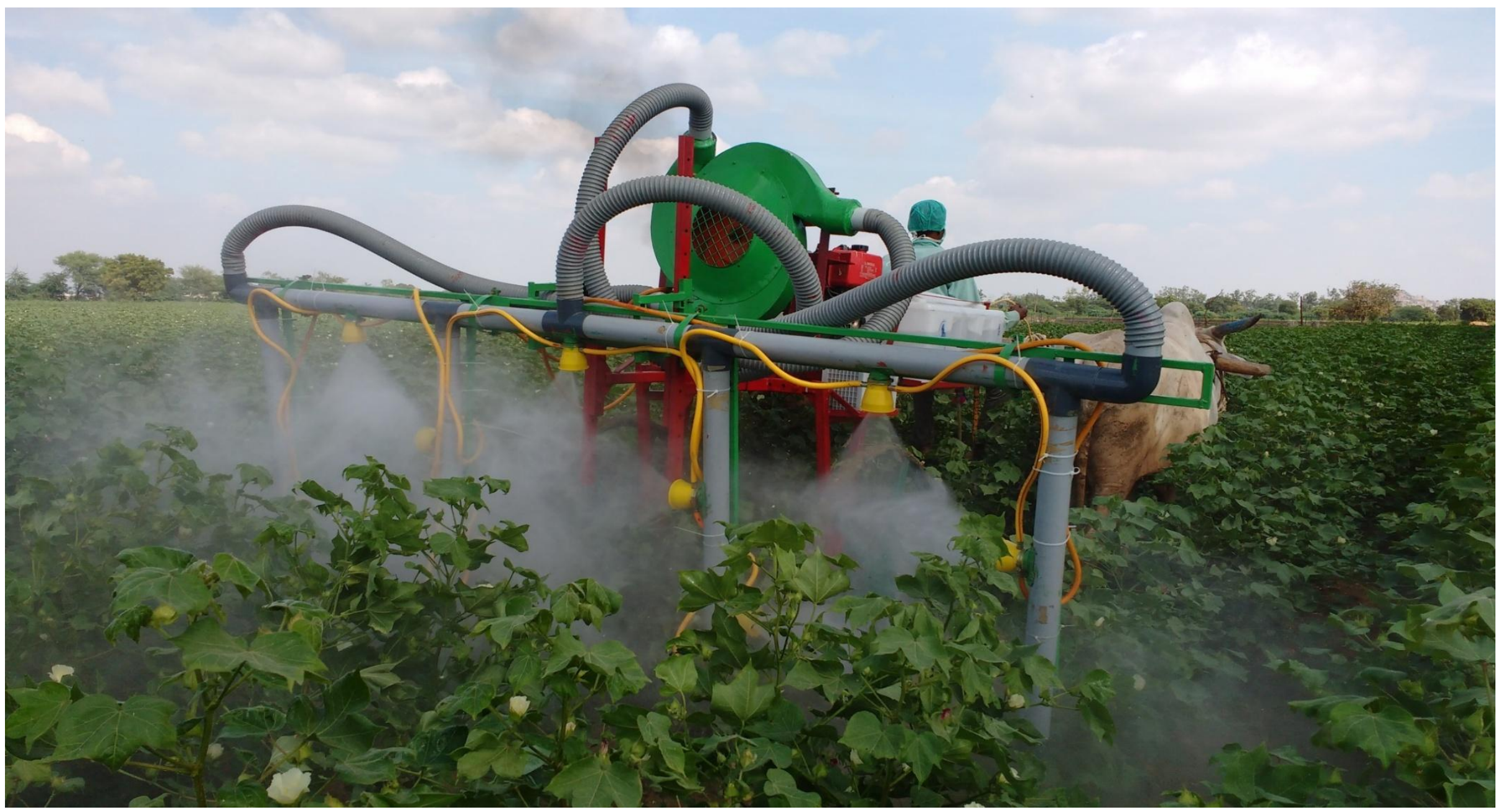

Plate.1 A rear view of bullock drawn air assisted intra canopy sprayer on cotton crop during field trials 


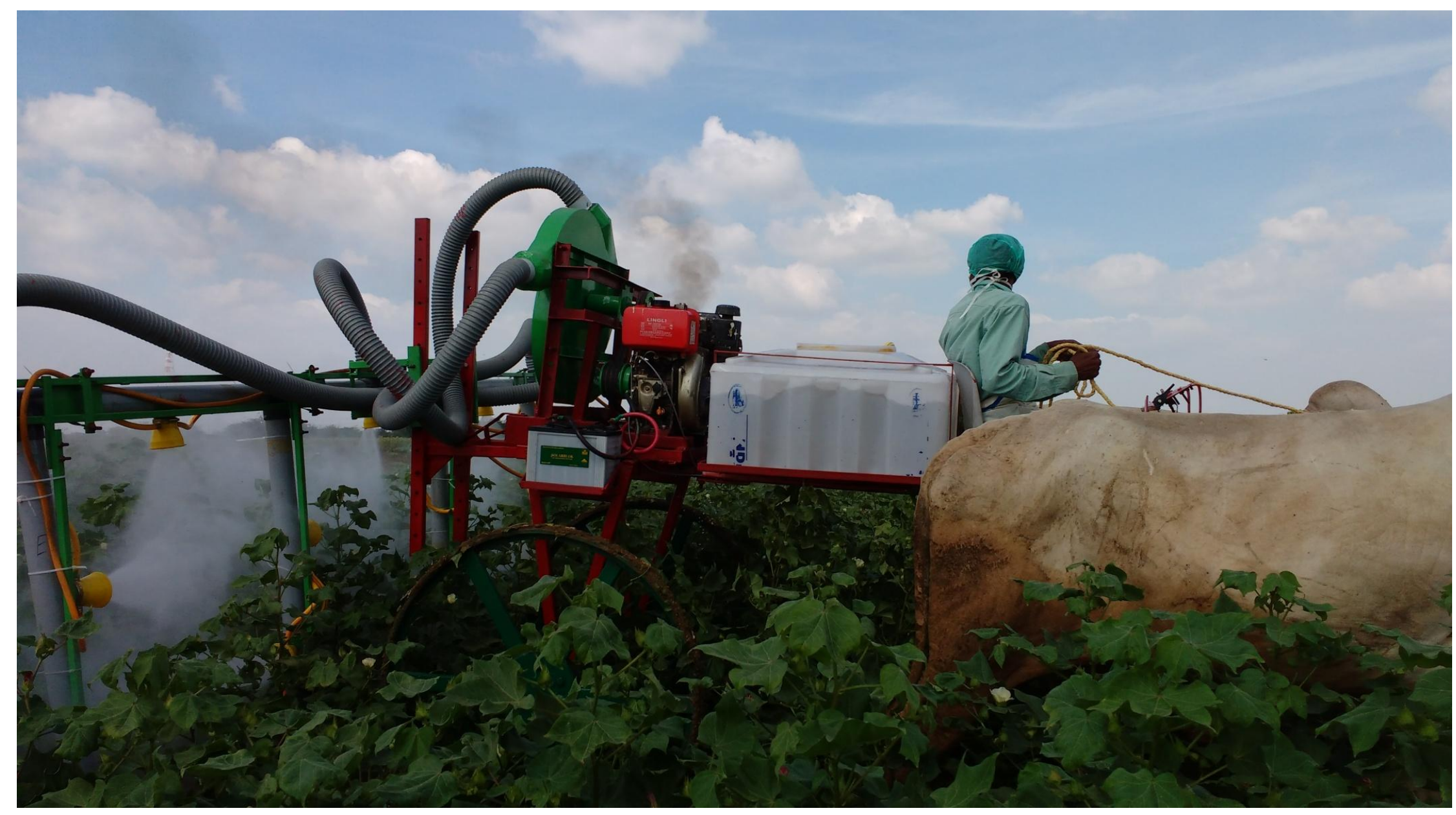

Plate.2 Side view of bullock drawn air assisted intra canopy sprayer on cotton crop during field trials 
Table.2 Biometric parameters of cotton crop

\begin{tabular}{|c|c|c|}
\hline Sl. No & Particulars & Cotton crop \\
\hline $\mathbf{1}$ & Variety & Bt MRC -7351 \\
\hline $\mathbf{2}$ & Average height of crop, mm & 1200 \\
\hline $\mathbf{3}$ & Stage of crop, days & 120 \\
\hline $\mathbf{4}$ & Row to row spacing, $\mathrm{mm}$ & 900 \\
\hline $\mathbf{5}$ & Plant to plant spacing, $\mathrm{mm}$ & 450 \\
\hline $\mathbf{6}$ & Number of bolls per plant & 60 \\
\hline
\end{tabular}

Table.3 Field performance of bullock drawn air assisted intra canopy sprayer on cotton crop

\begin{tabular}{|c|c|c|}
\hline Sl. No & Parameters & Values \\
\hline 1 & Variety & $\mathrm{B} t$ Cotton MRC7351 \\
\hline 2 & Row spacing, $\mathrm{mm}$ & 900 \\
\hline 3 & Plant to plant, $\mathrm{mm}$ & 450 \\
\hline 4 & No. of rows covered, No. & 3 \\
\hline 5 & Swath width, mm & 3200 \\
\hline 6 & Total boom length, mm & 3800 \\
\hline 7 & Operating pressure, $\mathrm{kg} \mathrm{cm}^{-2}$ & 10 \\
\hline 8 & Air velocity, $\mathrm{m} \mathrm{s}^{-1}$ & 12 \\
\hline 8 & Discharge rate, $1 \mathrm{~h}^{-1}$ & 960 \\
\hline 9 & Speed of travel, $\mathrm{km} \mathrm{h}^{-1}$ & 2.7 \\
\hline 10 & Draft, $\mathrm{N}$ & 758.82 \\
\hline 11 & Size of field, ha & 1 \\
\hline 12 & Field capacity, ha $\mathrm{h}^{-1}$ & 0.80 \\
\hline 14 & Quantity of chemical solution, $1 \mathrm{ha}^{-1}$ & 1200 \\
\hline 15 & Saving in cost, $\%$ & 82.24 \\
\hline 16 & Saving in time, $\%$ & 88.43 \\
\hline
\end{tabular}

The experiment was conducted at research farm for spraying on cotton crop using bullock drawn air assisted intra canopy sprayer. This sprayer was tested using a pair of bullock (Breed: Khillari) under physiological limits of bullocks with visual fatigue symptoms. The average field capacity of air assisted intra canopy sprayer for spraying on cotton crop was found to be $0.80 \mathrm{ha} \mathrm{h}^{-1}$. The average draft observed was 758.82 N. Saving in cost and time obtained was 82.24 and $88.43 \%$ respectively for air assisted intra canopy sprayer for spraying on cotton crop. The physiological response of bullocks and fatigue score for spraying operation was within the limit.

\section{References}

Adekunle, T. O., Olawale, O. O., Dalyop I. and Abimbola, S. I., 2008, The design of a closed-type-impeller blower for a $500 \mathrm{~kg}$ capacity rotary furnace. $A u J$. T., 12(1): 50-56.

Anibude, E.C., Jahun, R.F and Abubakar, M.S., 2016, Development of an animal drawn hydraulic boom sprayer. American Journal of Engineering Research (AJER)., 5(2):222-228.

Kaul, R. N. and Suleiman, M. L., 1990, Introduction to crop protection machinery. ABUCONS (Nig.) Ltd. Book Series, A.B.U., Press, Zaria, 
Nigeria: 100

Mathew, V. J., Dash, S. K., Das, D. K. and Pradhan, S. C., 1992, Development and testing of power tiller operated boom sprayer, $A M A$, 23(4): 25-27

Narang, S., Agrawal, K. N. and Singh, R. C., 2013, Development of power tiller operated Intra Canopy sprayer for cotton and pigeon pea crops. Agril. Engg. Today, 37(2): $17-22$
Veerangouda, M., Prakash, K. V., Jagjivan, R. and Neelakantayya, G., 2014. Development and evaluation of bullock drawn engine operated high clearance sprayer for pigeon pea crop. Kar. J. Agric. Sci., 7(1): 207-211.

Sharma, N. D. and Mukesh., 2010, A text book of Farm Machinery Design Principles and Problems. Jain brothers 16/873, East parkroad, Karol bagh, New Delhi.

\section{How to cite this article:}

Satyanarayan, K.V. Prakash, M. Anantachar, M. Veerangouda, Satyanarayana Rao and Sreenivas, A.G. 2019. Performance Evaluation of Air Assisted Intra Canopy Sprayer in Cotton Crop. Int.J.Curr.Microbiol.App.Sci. 8(11): 159-166.

doi: https://doi.org/10.20546/ijcmas.2019.811.020 